\title{
Is Perpendicular Double Two-Hole Plates Fixation Superior to Single Four-Hole Plate Fixation to Treat Mandibular Symphysis Fracture?-A Finite Element Study
}

\author{
Li-Ren Chang ${ }^{1,2}$, Ya-Pei Hou ${ }^{1}$ and Ting-Sheng Lin $^{3, *}$ \\ 1 Department of Plastic and Reconstructive Surgery, E-Da Hospital, Kaohsiung 824, Taiwan; \\ clrfyl@hotmail.com (L.-R.C.); nang691827@gmail.com (Y.-P.H.) \\ 2 College of Medicine, I-Shou University, Kaohsiung 824, Taiwan \\ 3 Department of Biomedical Engineering, I-Shou University, Kaohsiung 824, Taiwan \\ * Correspondence: tslin@isu.edu.tw
}

Citation: Chang, L.-R.; Hou, Y.-P.; Lin, T.-S. Is Perpendicular Double Two-Hole Plates Fixation Superior to Single Four-Hole Plate Fixation to Treat Mandibular Symphysis Fracture?-A Finite Element Study. Appl. Sci. 2021, 11, 8629. https:// doi.org/10.3390/app11188629

Academic Editor: José A. F. O. Correia

Received: 24 August 2021

Accepted: 13 September 2021

Published: 16 September 2021

Publisher's Note: MDPI stays neutral with regard to jurisdictional claims in published maps and institutional affiliations.

Copyright: (C) 2021 by the authors. Licensee MDPI, Basel, Switzerland. This article is an open access article distributed under the terms and conditions of the Creative Commons Attribution (CC BY) license (https:/ / creativecommons.org/licenses/by/ $4.0 /)$.

\begin{abstract}
The effectiveness of a single four-hole plate (S4HP), perpendicularly oriented four-hole and two-hole plate (Per4H2HP), and perpendicularly oriented double two-hole plate (PerD2HP) for the fixation of a mandibular fracture was studied. A finite element analysis of the mandibular symphysis fractures treated with S4HP, Per4H2HP, and PerD2HP was performed. All surface nodes were fixed in the mandibular condyle region and occlusal muscle forces were applied. The maximal von Mises stress (MaxVMS) values of the plates, screws and screw holes were investigated. The displacement of the fracture site on the lower border of the mandibular symphysis was recorded. The displacement on the lower border of the fracture sites in the S4HP group was greater than that in the Per4H2HP group and the PerD2HP group. There was no eversion at the fracture site among all groups. Both the S4HP and Per4H2HP groups showed stress concentrations on the screws close to the fracture site. The MaxVMS increased when the number of screw holes on the mandibular anterior lower border decreased. The displacement of the fracture site and eversion with Per4H2HP and PerD2HP were far lower than those with S4HP. PerD2HP is a stable and green fixation technique for mandibular symphysis fractures.
\end{abstract}

Keywords: mandibular fracture; perpendicular double 2-hole plate; perpendicular 4-hole-2-hole plate; finite element analysis

\section{Introduction}

Mandibular symphysis fractures are the most common types of facial bone fractures [1,2] and account for 13.8-27.5\% of all mandible fractures [3-6]. The purpose of treatment is adequate reduction with stable internal fixation to decrease the micromotion to less than $150 \mu \mathrm{m}$ to minimize nonunion [7-9], restore occlusion, and restore mastication function. Currently, microplates, miniplates, locking plates, reconstruction plates, compression plates [10], and lag screws are used for internal fixation. According to Arbag [11], double-plate fixation is more stable than single-plate fixation. Ji et al. showed that double four-hole plate fixation has lower stress than a single four-hole plate, regardless of the location of biting force (inter-cuspal, incisal, and left unilateral molar) [12]. Therefore, the current popular approach is to use the parallel double four-hole plates (ParD4HP) oriented along Champy's ideal osteosynthesis line on the mandibular anterior lower border (buccal side). The fracture pattern on the symphysis area is usually simple, but the forces acting on this region are complex. The ParD4HP method was reported to be able to sustain the negative bending moments produced by the masseter and temporalis muscles [13], which contract to produce tension force on the lower margin of the mandible and compression force on the gingiva area [14]. It can also resist the light shear force [15] but high torsion moment $[14,16]$ on the mandibular symphysis area. The discussion about the best internal 
fixation method [17] has not been extensive because the number and orientation of plates seems straightforward, and experience is the key factor [18]. However, if mandibular symphysis fractures are accompanied by body, angle, or subcondylar fractures, parallel double-plate fixation on the anterior/buccal side alone cannot prevent the posterior/lingual side from separation, thus causing inadequate reduction, malocclusion, and widening of the inter-gonial distance $[19,20]$. If subcondylar fractures are to be treated conservatively, fixation on the mandibular symphysis must be very stable to maintain the width of the mandible [21].

Owing to the advantages of increased calculation capacity of the computer, costefficiency and the consistency of the test protocol, finite element (FE) analysis has become a powerful approach for biomechanical research [22-26]. Despite irregular geometry and uncertain loading conditions, FE modeling can achieve a three-dimensional representation of the biomechanical response for the internal or external structure. In 2006, Kimura et al. used three-dimensional finite element analysis to study the effectiveness of perpendicular double four-hole plate (PerD4HP) fixation on a mandibular symphysis fracture [18]. They found that PerD4HP was more suitable and stable than ParD4HP in the fixation of mandibular symphysis fractures. The maximal stress of screw holes was significantly lower in the PerD4HP group than that in the ParD4HP group, indicating the presence of a stable fixation [18]. However, plate-screw stress and displacement showed no significant differences. Because the strain and displacement on the lingual site of the mandibular symphysis fracture are higher than those on the buccal side [15], the gap on the margin of the fracture site is a direct indicator of stability [18]. The displacement of fracture sites by Kimura et al. was $171 \mu \mathrm{m}$ (range, 10-310 $\mu \mathrm{m}$ ), which is stable enough under usual conditions unless the maximal biting force is applied.

The number of screws performed an important role in the stress sharing of the fixation plates. Traditionally, four-hole plate fixation with two holes on each side, with or without central extension, is the most popular method. Kimura et al. [18] and Ji et al. [12] pointed out that the maximum von Mises stress was concentrated on the two central screws near the fracture site despite the single four-hole plate (S4HP), ParD4HP, or PerD4HP. Kharmanda et al. proposed that using only two screws on the compression zone of the mandibular symphysis fracture did not affect the stability [22], and Ji et al. found that the stress extended to half of the outer two holes on the lower four-hole plate in the PerD4HP fixation. In 2020, Chang et al. proposed that a pair of two-hole plates on both ends of the osteotomy line shared the shear stress at two sites and therefore sustained more shearing force than a four-hole plate alone [23]. Based on the above reasoning, the author wanted to understand the shift of the stress on the plates, screws, and screw holes by adding a two-hole plate inferior to the S4HP, resulting in a Per4H2HP fixation. Furthermore, we investigated whether decreasing the number of screws from four to two holes maintained stability in perpendicularly oriented plates. By saving the fixation material without sacrificing stability, a green fixation method, which indicated fewer plates and screws are needed for the osteosynthesis, can be achieved.

\section{Materials and Methods}

The geometry of the mandibular bone was obtained from the computed tomographic images of the Sawbone 1337-3 model (Sawbone; Pacific Research Laboratories Inc., Vashon Island, WA, USA) at $0.625 \mathrm{~mm}$ intervals and digitized into the DICOM format. The geometry of the miniplates and screws was obtained from the manufacturer-provided information of the commercially available product for plates (10-51204 four-hole plate, thickness, $1.0 \mathrm{~mm}$; bar, $12 \mathrm{~mm}$ straight gold; MONDEAL MEDICAL SYSTEM GMBH, Mühlheim a. d. Donau, Germany) and screws (10-82009 CF Screw; \&, 2.0 mm; length, 9 mm, gold; MONDEAL MEDICAL SYSTEM GMBH, Mühlheim a. d. Donau, Germany).

Three-dimensional solid models of different miniplate fixations on the mandible bone were reconstructed and assembled using a commercial software application (SolidWorks 2008; Dassault Systèmes SolidWorks Corporation, Waltham, MA, USA). The integrated 
model was imported into the finite element (FE) package (ANSYS 19.0, ANSYS Inc., Canonsburg, PA, USA) and meshed using a 3D 10-node tetrahedral structure with an element size of $1.4 \mathrm{~mm}$ after the convergence of the FE model was calculated. Since the objective of this study was focused on the configuration of fixation, the interface between each component was assumed to be bonded and the friction between each component was ignored for saving calculation time. A $1 \mathrm{~mm}$ gap was created in the midline of the mandibular symphysis to simulate a fracture line. Three groups of fixation were studied (Table 1.). The first group is single four-hole plate group (S4HP). We fixed a single centrally extended four-hole plate (S4HP) on the anterior lower border of the mandible, $5 \mathrm{~mm}$ below the mental foramen. The second group is the perpendicular four-hole and two-hole plate group (Per4H2HP). A two-hole plate (2HP) was added on the inferior border of the S4HP group in a perpendicular orientation. The $2 \mathrm{HP}$ was fabricated with a six-hole plate, which was cut in half to form a pair of three-hole plates. The central hole of the plate acted as the central extension, and two lateral holes were used for fixation. The third group is the perpendicular double two-hole plate group (PerD2HP). A pair of 2HPs were fixed on the anterior lower border and inferior border of the mandible.

Table 1. Schematic of solid models used in this study. S4HP: a centrally extended single four-hole plate fixed on the mandibular anterior lower border; Per4H2HP: perpendicularly oriented S4HP fixed on the mandibular anterior lower border and 2HP fixed on the mandibular inferior border; PerD2HP: perpendicularly oriented 2HP fixed on the mandibular anterior lower border and the other $2 \mathrm{HP}$ fixed on the mandibular inferior border.

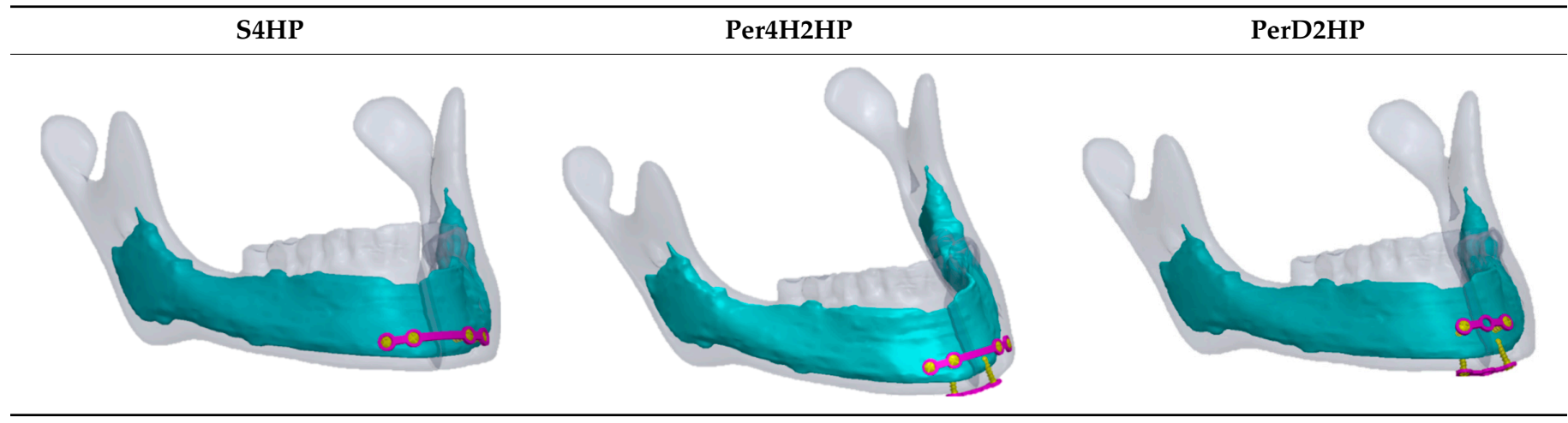

The mandible bone and miniplate system in the FEA model were both assumed to be composed of homogeneous, isotropic, and linear elastic materials. The mechanical properties, including the Young's modulus (E) and Poisson's ratio $(v)$ of the cortical bone $(\mathrm{E}=14,000 \mathrm{MPa}, v=0.3)$, cancellous bone $(\mathrm{E}=1500 \mathrm{MPa}, v=0.3)$, and miniplates and screws ( $\mathrm{E}=115,000 \mathrm{MPa}, v=0.35)$ were used in this study [27]. The interfaces between the bone, plate, and screws were all assumed to be bonded; however, the bone surface of the fracture incision site was set in contact. Because the stress around the fixation system was the major concern in this study, the interior structure of the teeth was not modelled and the mechanical properties were assumed as the cortical bone.

After the mesh models were generated, the acting muscles and their vectors (force and direction) were applied according to the study by Ramos et al. (Table 2 and Figure 1) [28]. All surface nodes were fixed in the mandibular condyle region. The maximum von Mises stress (MaxVMS) of the plates, screws, and screw holes were evaluated to study the stress originally generated in S4HP group, the shifting of stress after adding a perpendicularly oriented 2HP in Per4H2HP group, and the effects on stress when the plate holes on the anterior lower border of the plate were reduced in the PerD2HP group. The MaxVMS of the plates and screws were compared with the yield strength of the plate at $830 \mathrm{MPa}$, and the MaxVMS of the screw holes was compared with the tensile strength of the mandible bone at $85 \mathrm{MPa}$ [29]. The stability of the fixation was evaluated by measuring the displacement of the inferior border of the mandibular fracture site. 
Table 2. Forces and acting direction of the major muscles applied onto the mandible for occlusion in the finite element analysis [28].

\begin{tabular}{ccccc}
\hline \multirow{2}{*}{ Muscles Actions } & Ref. & \multicolumn{3}{c}{ Loads (N) } \\
\cline { 3 - 5 } & & X axis & Y axis & Z axis \\
\hline Deep masseter & A, B & 7.776 & 127.23 & 122.68 \\
\hline Superficial masseter & C, D & 12.873 & 183.5 & -77.3 \\
\hline Medial pterygoid & E, F & 140.38 & 237.8 & -0.13 \\
\hline Temporalis & G, H & 0.064 & 0.37 & -7.44 \\
\hline Medial temporalis & I, J & 0.97 & 5.68 & \\
\hline
\end{tabular}

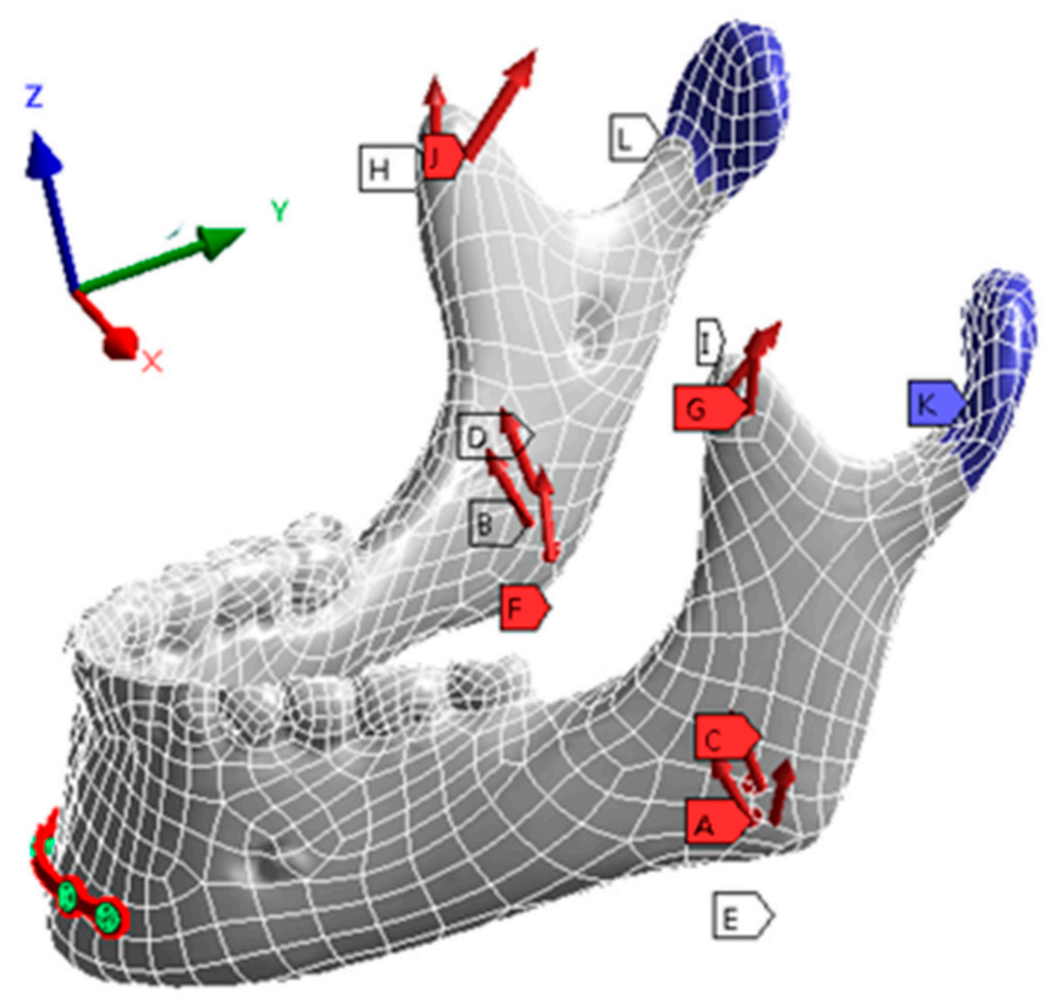

Figure 1. Muscle action for occlusion on the mandible.

\section{Results}

\subsection{S4HP Group}

The MaxVMS of the plate was $381.03 \mathrm{MPa}$, which was lower than the yield strength of the plate (Figure 2a). The MaxVMS values of the screws from the right side to the left side were 32.897 $\mathrm{MPa}, 107.66 \mathrm{MPa}, 114.35 \mathrm{MPa}$, and 88.145 MPa. These values were all lower than the yield strength of the screw (Figure $2 b$ ). The MaxVMS values of the screw holes from the right side to the left side were $13.145 \mathrm{MPa}, 10.554 \mathrm{MPa}, 14.16 \mathrm{MPa}$, and $32.68 \mathrm{MPa}$. These values were lower than the tensile strength of the mandible (Figure $2 \mathrm{c}$ ). The displacement on the mandibular lower border was $0.311 \mathrm{~mm}$, and the fracture site was everted.

\subsection{Per $4 \mathrm{H} 2 \mathrm{HP}$}

The MaxVMS value of the plate on the mandibular anterior lower border was $407.31 \mathrm{MPa}$ and that on the mandibular inferior border was $550.44 \mathrm{MPa}$. These values were lower than the yield strength of the plate (Figure 3a). The MaxVMS values of the screws on the mandibular anterior lower border from the right side to the left side were $111.18 \mathrm{MPa}, 155.79 \mathrm{MPa}$, 310.73 MPa, and 98.197 MPa. The MaxVMS values of the screws on the mandibular inferior border from the right side to the left side were $185.45 \mathrm{MPa}$ and $259.18 \mathrm{MPa}$. All the data 
were lower than the yield strength of the screws (Figure 3b). The MaxVMS values of the screw holes on the mandibular anterior lower border from the right side to the left side were 23.278 MPa, 24.611 MPa, 35.14 MPa, and 64.483 MPa. The MaxVMS values of the screw holes on the mandibular inferior border from the right side to the left side were $58.582 \mathrm{MPa}$ and $98.035 \mathrm{MPa}$. The MaxVMS of the screw holes on the left side was higher than the yield strength of the screw (Figure 3c). The displacement on the mandibular lower border was $0.034 \mathrm{~mm}$, and there was no prominent eversion at the fracture site.

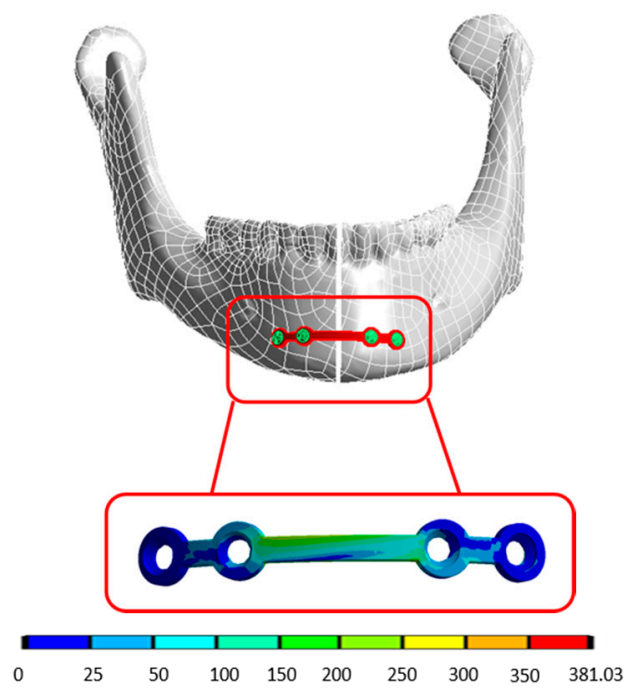

(a)

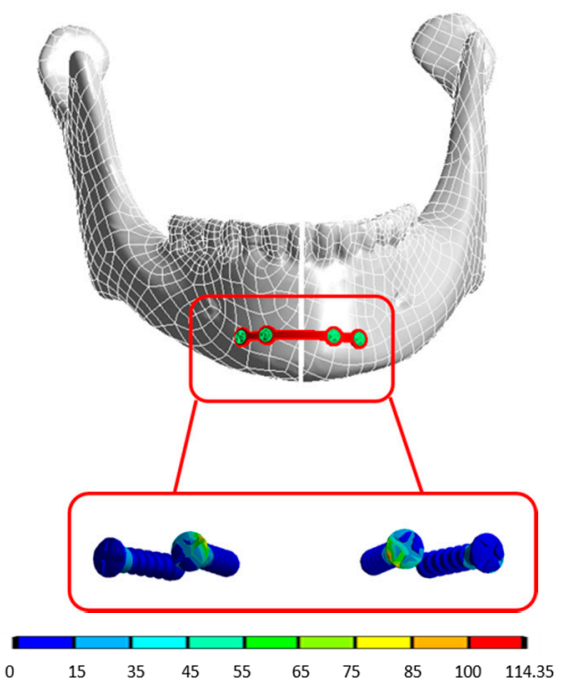

(b)

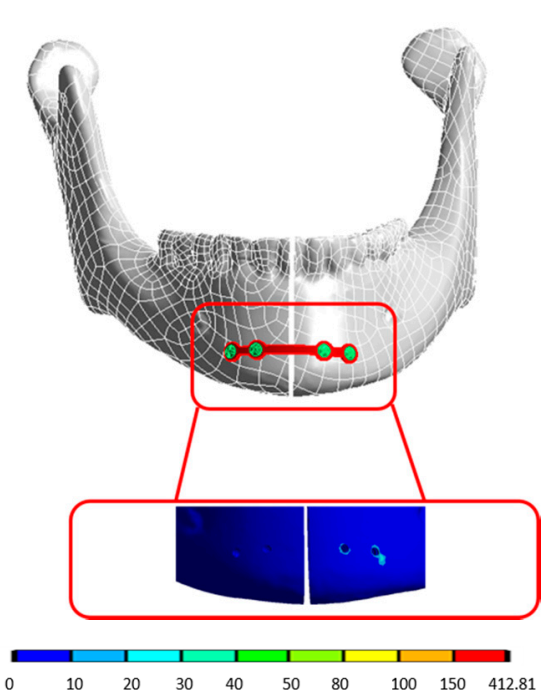

(c)

Figure 2. Stress distribution of S4HP. (a) plate; (b) screws; (c) screw holes. (Unit: MPa).

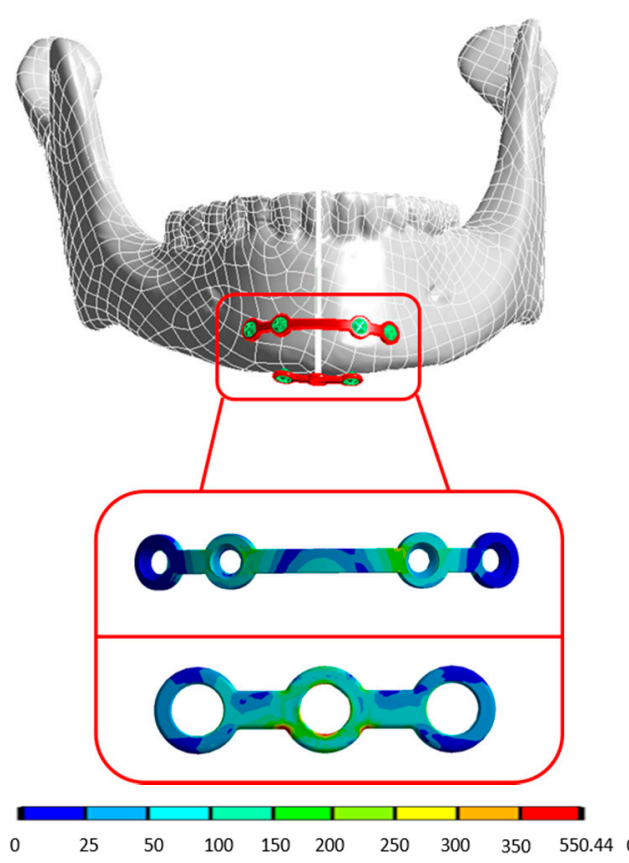

(a)

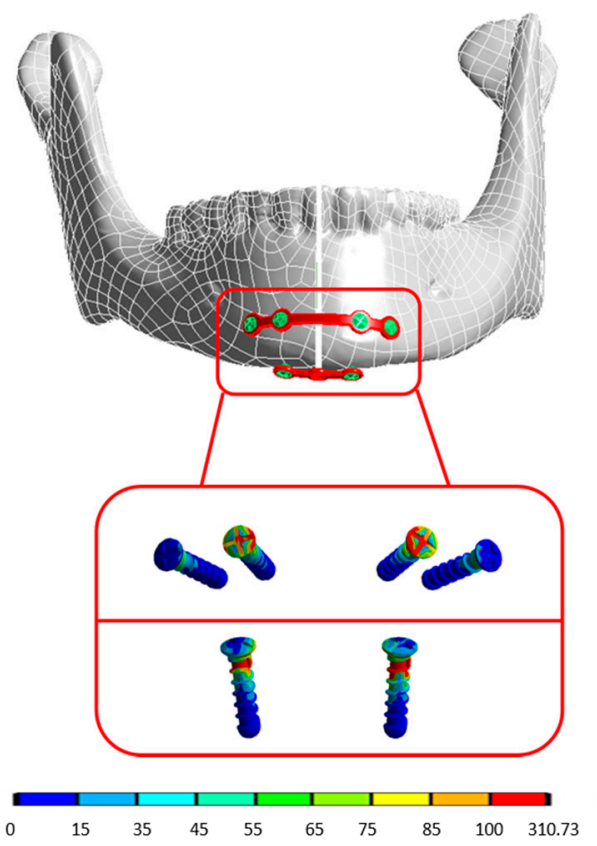

(b)

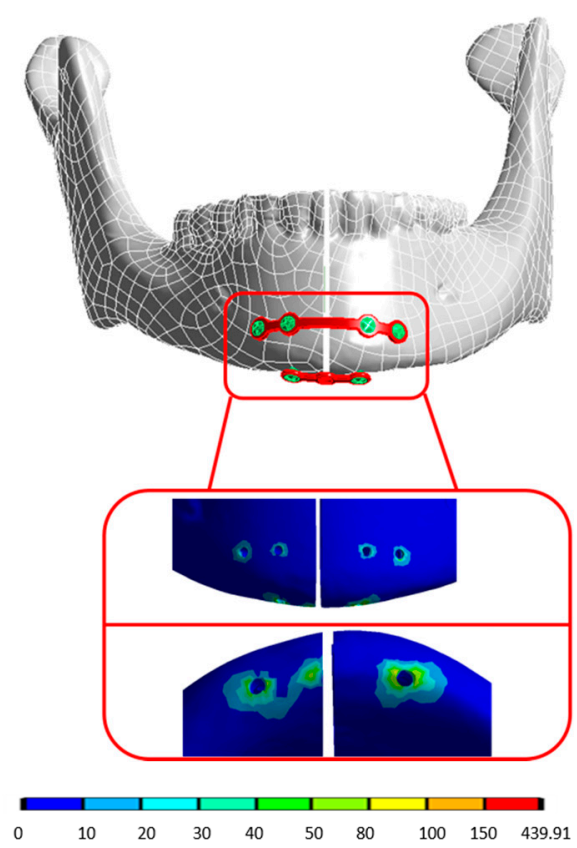

(c)

Figure 3. Stress distribution of Per4H4HP. (a) plate; (b) screws; (c) screw holes. (Unit: MPa).

\subsection{PerD2HP}

The MaxVMS of the plate on the mandibular anterior lower border was $354.63 \mathrm{MPa}$ and that on the mandibular inferior border was $562.58 \mathrm{MPa}$. These values were lower 
than the yield strength of the plate (Figure 4a). The MaxVMS values of the screws on the mandibular anterior lower border from the right side to the left side were $140.4 \mathrm{MPa}$ and $100.32 \mathrm{MPa}$. The MaxVMS values of the screws on the mandibular inferior border from the right side to the left side were 442.19 MPa and 107.05 MPa. All the data were lower than the yield strength of the screws (Figure 4b). The MaxVMS of the screw holes on the mandibular anterior lower border from the right side to the left side were $80.758 \mathrm{MPa}$ and $31.519 \mathrm{MPa}$. These values are lower than the tensile strength of the mandible. The MaxVMS of the screws on the mandibular inferior border from the right side to the left side were 132.03 MPa and 39.189 MPa. The MaxVMS of the screw on the right side was higher than the tensile strength of the mandible (Figure 4c). The displacement on the mandibular lower border was $0.025 \mathrm{~mm}$, and there was no prominent eversion at the fracture site.

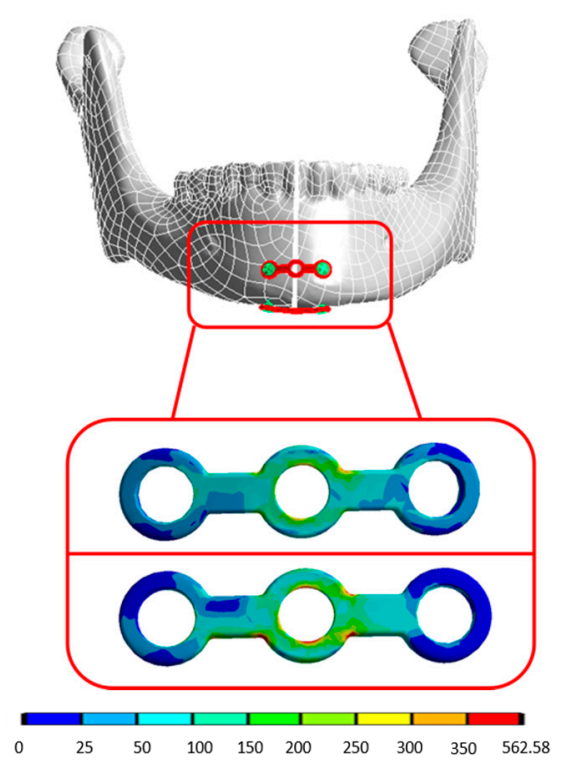

(a)

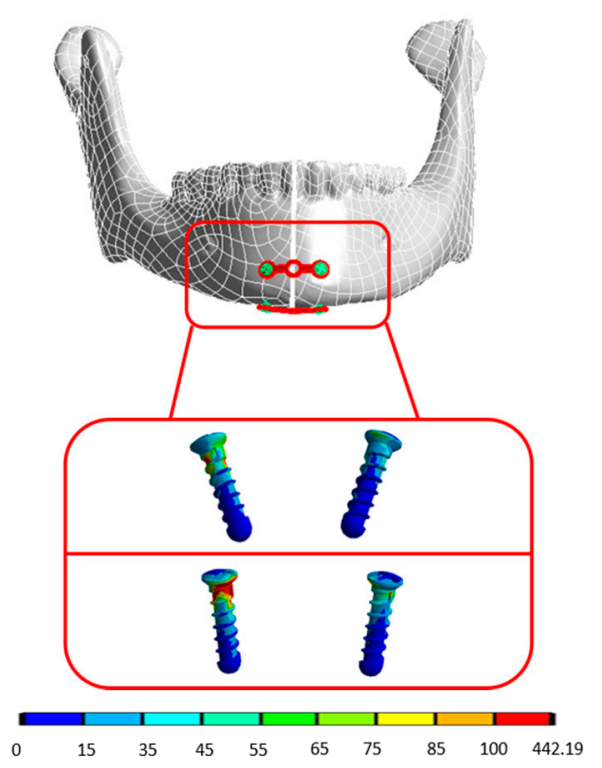

(b)

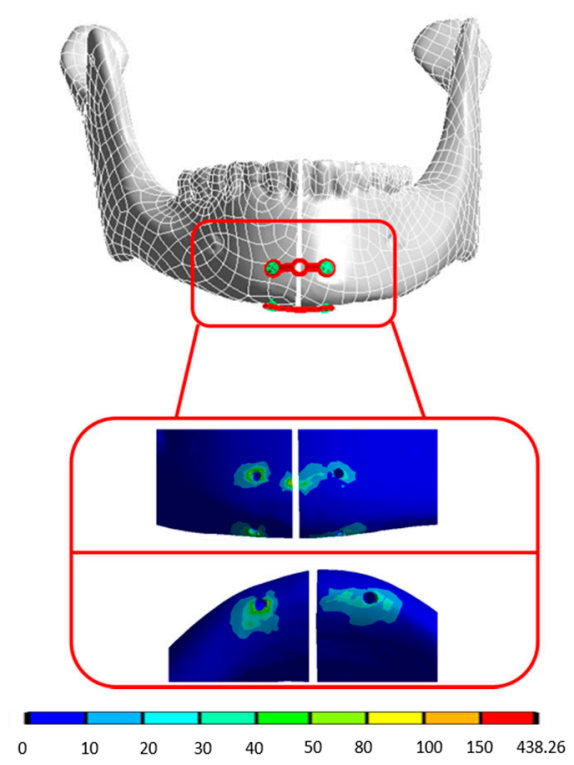

(c)

Figure 4. Stress distribution of PerD2HP. (a) plate; (b) screws; (c) screw holes. (Unit: MPa).

\section{Discussion}

In this study, the most important finding was the significant difference in displacement between the S4HP and perpendicular plate fixation. There was eversion at the fracture site, and the displacement was $0.311 \mathrm{~mm}$ in the S4HP group. When $2 \mathrm{HP}$ was added to the mandibular inferior border (Per4H2HP), the displacement was $0.034 \mathrm{~mm}(-89.06 \%)$, and there was no eversion at the fracture site. Furthermore, when the holes on the plate on the mandibular anterior lower border decreased from four (Per4H2HP) to two (PerD2HP), the displacement was $0.025 \mathrm{~mm}(-91.96 \%)$, and there was no eversion at the fracture site. The apparently lower displacement on the fracture site revealed that the PerD2HP group was as stable as the Per4H2HP group and more stable than the S4HP group.

In 1992, Rudderman and Mullen proposed that the best way to fix the mandible fracture is to orient the plates on different axes [30]. However, the concept of perpendicular plate fixation has not been explored. Lovald et al. found that a high-tension force was present on the lower margin of the mandibular symphysis fracture and high compression force, on the gingiva area. In addition, the strain and deformity on the lingual side were larger than those on the buccal side [15], thus causing mandible eversion. To prevent this, thick plates or over-bent plates were used [31]. However, thick plates have a high strain and stress shielding effect, but widening the plate can decrease the strain and increase the force against fracture site eversion [15]. It is not easy to increase the width of the plate, but ParD4HP can achieve this goal. Furthermore, PerD4HP increased the distance between the plates along different axes, which might be better than the distance achieved with ParD4HP. 
The first study on PerD4HP in the fixation of a mandibular symphysis fracture was performed by Kimura et al. in 2006 using FEA in different computer models [18]. In 2010, Arora et al. used FEA to show that the PerD4HP technique is suitable for fixation of mandibular symphysis fractures [10]. In 2011, Viera et al. studied a single four-hole plate (S4HP), ParD4HP, PerD4HP, and lag screw technique for fixation of mandibular symphysis fracture using a polyurethane model [17]. Kimura et al. showed that both PerD4HP and ParD4HP had more stable fixation than the S4HP due to significantly lower plate-screw strain, lower screw hole strain, and less displacement [18]. Vieira et al. found that the PerD4HP and lag screw had equal stability to resist high displacement at $5 \mathrm{~mm}$ and $10 \mathrm{~mm}$, but there was no difference between the ParD4HP and PerD4HP [17] in displacements less than $5 \mathrm{~mm}$. Arora et al. also proposed that PerD4HP resisted more vertical biting force and limited horizontal displacement compared with ParD4HP, thus favoring bone healing [10]. Kimura explained why PerD4HP is more stable. When the force acts on the molar teeth, a shearing force and torsion force would cause the displacement to move inferiorly and laterally. The stress of the ParD4HP was on the screw-plate junction, but the stress of the PerD4HP was on the plate and thus resisted the lateral displacement [18]. Although there was no significant difference between ParD4HP and PerD4HP, the stress of the PerD4HP screw holes was significantly lower than that of the ParD4HP, indicating stable fixation.

Kimura et al. found that the perpendicularly oriented double plates had a significantly smaller fracture site displacement than the single plate [18]. Vieira et al. proposed that perpendicularly oriented fixation of double plates in the tension zone is more stable than the fixation of a single plate [17]. By using a 2HP on the mandibular anterior, stable fixation was achieved similar to that with a $4 \mathrm{HP}$ in the perpendicular fixation method.

\subsection{Stress Shift on Plates}

In this study, the MaxVMS of the plates in all the groups was lower than the yield strength of the plate $(830 \mathrm{MPa})$. Therefore, there was no destruction or deformity of the plates in the computer simulation. In the Per4H2HP group, the $2 \mathrm{HP}$ on the mandibular inferior border sustained a MaxVMS of 550.44 MPa (Table 3). This proved that the mandibular inferior border plate shared the stress in the tension zone. In the PerD2HP group, the number of plate holes on the mandibular anterior lower border was half of that in the Per4H2HP group. However, the MaxVMS on the mandibular anterior lower border decreased by $12.9 \%$ and the MaxVMS on the mandibular inferior border only increased by $2.2 \%$. This means that the $2 \mathrm{HP}$ on the mandibular anterior lower border is strong enough not to increase loading on the mandibular inferior border.

Table 3. The MaxVMS of plates in three fixation groups on mandibular symphysis fracture (unit: $\mathrm{MPa}$ ).

\begin{tabular}{cccc}
\hline & S4HP & Per4H2HP & PerD2HP \\
\hline Anterior lower border & 381.03 & 407.31 & 354.63 \\
\hline Inferior border & & 550.44 & 562.58 \\
\hline
\end{tabular}

\subsection{Stress Shift on Screws}

In this study, the MaxVMS of screws in all groups was lower than the yield strength of the screw $(830 \mathrm{MPa})$. Therefore, there was no destruction or deformity of the screws in the computer simulation. Both the S4HP and Per4H2HP groups showed stress concentration on the screws close to the fracture site, similar to the results of Kimura et al. In the PerD2HP group, the MaxVMS of the screws on the mandibular inferior border shared stress. From S4HP to Per4H2HP, the MaxVMS of the screws on the mandibular anterior lower border increased. From Per4H2HP to PerD2HP, the MaxVMS of the screws on the mandibular anterior lower border decreased, but that on the mandibular inferior border increased by $138.44 \%$ on the right-side screws and decreased by $142.11 \%$ on the left side (Table 4 ). This 
means that decreasing the number of plate holes on the mandibular anterior lower border increased the MaxVMS on the inferior border.

Table 4. The MaxVMS of screws in three fixation groups with mandibular symphysis fracture (Unit: MPa).

\begin{tabular}{|c|c|c|c|c|c|}
\hline Muscles Actions & & & S4HP & Per4H2HP & PerD2HP \\
\hline \multirow{4}{*}{$\begin{array}{l}\text { Anterior lower } \\
\text { border }\end{array}$} & \multirow{2}{*}{ Right } & Outer hole & 32.897 & 111.18 & \multirow{2}{*}{140.4} \\
\hline & & Medial hole & 107.66 & 155.79 & \\
\hline & \multirow{2}{*}{ Left } & Outer hole & 114.35 & 310.73 & \multirow{2}{*}{100.32} \\
\hline & & Medial hole & 88.145 & 98.197 & \\
\hline \multirow{2}{*}{ Inferior border } & Right & & & 185.45 & $442.19(+138.44 \%)$ \\
\hline & Left & & & 259.18 & $107.05(-142.11 \%)$ \\
\hline
\end{tabular}

$\%$ denotes comparison of the stress of the screws between the Per4H2HP and PerD2HP.

\subsection{Stress Shift on Screw Holes}

The MaxVMS of the screw holes in each group on the mandibular anterior lower border was lower than the tensile strength of the mandible ( $85 \mathrm{MPa})$. Therefore, there should be no bony destruction. When the number of screw holes decreased from four (Per4H2HP) to two (PerD2HP), the MaxVMS increased on the right side. However, the MaxVMS of the left side Per4H2HP screw holes and right side PerD2HP screw holes on the mandibular inferior border were higher than $85 \mathrm{MPa}$ (Table 5). Consequently, bony destruction of the screw holes may occur. The screw holes seem to be the key point of the fixation system. Because the MaxVMS of plates and screws were lower than the yield strength, breaking of plates and screws did not occur. The S4HP group has larger displacement than Per4H2HP and PerD2HP, and this result suggested that both groups using perpendicular double plates were more stable than the single plate. Therefore, it implied that the additional perpendicular plate might carry more occlusal stresses than S4HP group.

Table 5. The MaxVMS of screws in three fixation groups with mandibular symphysis fracture (Unit: MPa).

\begin{tabular}{|c|c|c|c|c|c|}
\hline Muscles Actions & & & S4HP & Per4H2HP & PerD2HP \\
\hline \multirow{4}{*}{$\begin{array}{l}\text { Anterior lower } \\
\text { border }\end{array}$} & \multirow{2}{*}{ Right } & Outer hole & 13.145 & 23.278 & \multirow{2}{*}{80.758} \\
\hline & & Medial hole & 10.554 & 24.611 & \\
\hline & \multirow{2}{*}{ Left } & Outer hole & 14.16 & 35.14 & \multirow{2}{*}{31.519} \\
\hline & & Medial hole & 32.68 & 64.483 & \\
\hline \multirow{2}{*}{ Inferior border } & Right & & & 58.582 & $132.03(+125.38 \%)$ \\
\hline & Left & & & 98.035 & $39.189(-60.02 \%)$ \\
\hline
\end{tabular}

$\%$ denotes comparison of the stress of the screws between the Per4H2HP and PerD2HP.

\subsection{Limitations}

This study focused mainly on the muscle forces acting on the mandibular symphysis fracture site and the force of $2 \mathrm{HP}$ in the inferior border to determine the force. However, the force acting on the molar teeth requires further investigation. There are seldom literatures mentioned about the scenario of the occlusal force after the fracture treatment. This study applied normal occlusal loadings which might be greater than that of posttreatment. Therefore, the stress level might be overrated since the occlusal function decreases after surgery. Moreover, the major concern of this study focused on the stress distribution around the fixation, and no force was directly applied to the teeth. Nevertheless, the simplification of the teeth in this finite element model was acceptable. However, the biomechanical effect of the dentition needs further investigation. Only static forces were applied in this study. 
Dynamic force with added force on the molar teeth or mandible angle might be needed to further confirm the stability of PerD2HP.

\section{Conclusions}

There was a shift in the stress on the plates, screws, and screw holes on the mandibular inferior border upon adding a $2 \mathrm{HP}$ inferior to the S4HP, resulting in a Per4H2HP fixation. Although the plates, screws, and screw holes on the mandibular inferior border sustained high stress in the Per4H2HP group and even higher stress in the PerD2HP group, perpendicularly oriented double plates fix both the tension and compression zones, and the displacement of the fracture site and eversion was far less than that with a S4HP. Therefore, this is a stable fixation method. In this study, a $2 \mathrm{HP}$ was as stable as a $4 \mathrm{HP}$ in the fixation of the mandibular anterior lower border. Molding the $2 \mathrm{HP}$ onto the mandibular surface is easier than molding the $4 \mathrm{HP}$, and fewer plates and screws are used. We conclude that PerD2HP is stable enough to fix a mandibular symphysis fracture.

Author Contributions: Conceptualization, L.-R.C.; funding acquisition, T.-S.L.; methodology, Y.-P.H. and T.-S.L.; project administration, L.-R.C. and T.-S.L.; supervision, L.-R.C. and T.-S.L.; validation, Y.-P.H. and T.-S.L.; writing - original draft, Y.-P.H. and L.-R.C.; writing — review and editing, Y.-P.H. and T.-S.L. All authors have read and agreed to the published version of the manuscript.

Funding: Work supported in part by MOST108-2221-E-214-009 from the Ministry of Science and Technology of Taiwan.

Institutional Review Board Statement: Not applicable.

Informed Consent Statement: Not applicable.

Data Availability Statement: The data presented in this study are available.

Conflicts of Interest: The authors declare no conflict of interest.

\section{References}

1. Erol, B.; Tanrikulu, R.; Görgün, B. Maxillofacial Fractures. Analysis of demographic distribution and treatment in 2901patients (25-year experience). J. Cranio-Maxillofac. Surg. 2004, 32, 308-313. [CrossRef]

2. Haug, R.H.; Prather, J.; Thomas Indresano, A. An epidemiologic survey of facial fractures and concomitant injuries. J. Oral Maxillofac. Surg. 1990, 48, 926-932. [CrossRef]

3. Ahmed, H.E.A.; Jaber, M.A.; Abu Fanas, S.H.; Karas, M. The pattern of maxillofacial fractures in Sharjah, United Arab Emirates: A review of 230 cases. Oral Surg. Oral Med. Oral Pathol. Oral Radiol. Endodontol. 2004, 98, 166-170. [CrossRef] [PubMed]

4. Boole, J.R.; Holtel, M.; Amoroso, P.; Yore, M. 5196 mandible fractures among 4381 active duty army soldiers, 1980 to 1998. Laryngoscope 2001, 111, 1691-1696. [CrossRef] [PubMed]

5. Brasileiro, B.F.; Passeri, L.A. Epidemiological analysis of maxillofacial fractures in Brazil: A 5-year prospective study. Oral Surg. Oral Med. Oral Pathol. Oral Radiol. Endodontol. 2006, 102, 28-34. [CrossRef]

6. Martini, M.Z.; Takahashi, A.; Oliveira Neto, H.G.d.; Carvalho Júnior, J.P.d.; Curcio, R.; Shinohara, E.H. Epidemiology of mandibular fractures treated in a Brazilian level I trauma public hospital in the city of São Paulo, Brazil. Braz. Dent. J. 2006, 17, 243-248. [CrossRef]

7. Lamphier, J.; Ziccardi, V.; Ruvo, A.; Janel, M. Complications of mandibular fractures in an urban teaching center. J. Oral Maxillofac. Surg. 2003, 61, 745-749. [CrossRef]

8. Søballe, K. Hydroxyapatite ceramic coating for bone implant fixation: Mechanical and histological studies in dogs. Acta Orthop. Scand. 1993, 64, 1-58. [CrossRef] [PubMed]

9. Tams, J.; Van Loon, J.-P.; Otten, B.; Bos, R.R.M. A computer study of biodegradable plates for internal fixation of mandibular angle fractures. J. Oral Maxillofac. Surg. 2001, 59, 404-407. [CrossRef] [PubMed]

10. Arora, L.; Bhardwaj, S.; Hashmi, G.S.; Anwar, S.F.; Rahman, S.A. Finite Element Analysis (FEA) of Perpendicular Plating Versus Conventional Plating in Mandibular Symphysis Fracture. J. Maxillofac. Oral Surg. 2020, 19, 143-148. [CrossRef]

11. Arbag, H.; Korkmaz, H.H.; Ozturk, K.; Uyar, Y. Comparative Evaluation of Different Miniplates for Internal Fixation of Mandible Fractures Using Finite Element Analysis. J. Oral Maxillofac. Surg. 2008, 66, 1225-1232. [CrossRef]

12. Ji, B.; Wang, C.; Liu, L.; Long, J.; Tian, W.; Wang, H. A biomechanical analysis of titanium miniplates used for treatment of mandibular symphyseal fractures with the finite element method. Oral Surg. Oral Med. Oral Pathol. Oral Radiol. Endodontol. 2010, 109, e21-e27. [CrossRef]

13. Madsen, M.J.; McDaniel, C.A.; Haug, R.H. A Biomechanical Evaluation of Plating Techniques Used for Reconstructing Mandibular Symphysis/Parasymphysis Fractures. J. Oral Maxillofac. Surg. 2008, 66, 2012-2019. [CrossRef] 
14. Tams, J.; van Loon, J.P.; Otten, E.; Rozema, F.R.; Bos, R.R.M. A three-dimensional study of bending and torsion moments for different fracture sites in the mandible: An in vitro study. Int. J. Oral Maxillofac. Surg. 1997, 26, 383-388. [CrossRef]

15. Lovald, S.; Baack, B.; Gaball, C.; Olson, G.; Hoard, A. Biomechanical Optimization of Bone Plates Used in Rigid Fixation of Mandibular Symphysis Fractures. J. Oral Maxillofac. Surg. 2010, 68, 1833-1841. [CrossRef]

16. Tams, J.; van Loon, J.P.; Rozema, F.R.; Otten, E.; Bos, P.R.M. A three-dimensional study of loads across the fracture for different fracture sites of the mandible. Br. J. Oral Maxillofac. Surg. 1996, 34, 400-405. [CrossRef]

17. Vieira e Oliveira, T.R.; Passeri, L.A. Mechanical Evaluation of Different Techniques for Symphysis Fracture Fixation-An In Vitro Polyurethane Mandible Study. J. Oral Maxillofac. Surg. 2011, 69, e141-e146. [CrossRef] [PubMed]

18. Kimura, A.; Nagasao, T.; Kaneko, T.; Miyamoto, J.; Nakajima, T. A comparative study of most suitable miniplate fixation for mandibular symphysis fracture using a finite element model. Keio J. Med. 2006, 55, 1-8. [CrossRef] [PubMed]

19. Chen, S.; Zhang, Y.; An, J.G.; He, Y. Use of two 2.0 mini-plates for width-controlling fixation of symphyseal/parasymphyseal fractures associated with bilateral condylar fractures: A retrospective investigation of 45 cases. Int. J. Oral Maxillofac. Surg. 2015, 44, e27-e28. [CrossRef]

20. Prein, J.; Lüscher, N.J. Anatomic Approaches. In Manual of Internal Fixation in the Cranio-Facial Skeleton: Techniques Recommended by the AO/ASIF Maxillofacial Group; Prein, J., Ed.; Springer: Berlin/Heidelberg, Germany, 1998; pp. 51-56.

21. Peterson, L.J. Peterson's Principles of Oral and Maxillofacial Surgery; PMPH-USA: Shelton, CT, USA, $2012 ;$ Volume 1.

22. Kharmanda, G.; Kharma, M.-Y. Evaluating the Effect of Minimizing Screws on Stabilization of Symphysis Mandibular Fracture by 3D Finite Element Analysis. J. Maxillofac. Oral Surg. 2017, 16, 205-211. [CrossRef] [PubMed]

23. Lin, T.-S.; Tsai, F.-D.; Chen, C.-Y.; Lin, L.-W. Factorial analysis of variables affecting bone stress adjacent to the orthodontic anchorage mini-implant with finite element analysis. Am. J. Orthod. Dentofac. Orthop. 2013, 143, 182-189. [CrossRef]

24. Manafi Khajeh Pasha, A.; Mahmoudi Sheykhsarmast, R.; Manafi Khajeh Pasha, S.; Khashabi, E. Influence of Treatment Plans on Stress and Deformation Distribution in Mandibular Implant-Supported Overdenture and Mandibular Bone under Traumatic Load: A 3D FEA. J. Med. Biol. Eng. 2021, 41, 543-557. [CrossRef]

25. Moiduddin, K. Implementation of Computer-Assisted Design, Analysis, and Additive Manufactured Customized Mandibular Implants. J. Med. Biol. Eng. 2018, 38, 744-756. [CrossRef]

26. Chang, L.-R.; Chen, C.-C.; Jeng, S.F.; Chen, Y.-R.; Hwang, L.-C.; Lin, T.-S. Investigation of a Modified Novel Technique in Bilateral Sagittal Splitting Osteotomy Fixation: Finite Element Analysis and In Vitro Biomechanical Test. BioMed Res. Int. 2020, 2020, 8707389. [CrossRef] [PubMed]

27. Chen, Y.-H. Biomechanical Analysis of Mandibular Symphyseal Fracture with Different Fixation Configurations. Master's Thesis, I-Shou University, Kaohsiung, Taiwan, 2016.

28. Ramos, A.; Completo, A.; Relvas, C.; Mesnard, M.; Simões, J.A. Straight, semi-anatomic and anatomic TMJ implants: The influence of condylar geometry and bone fixation screws. J. Cranio-Maxillofac. Surg. 2011, 39, 343-350. [CrossRef] [PubMed]

29. Kao, M.-H. Investigation of Intraoral Stability on Bilateral Sagittal Split Osteotomy with Various Fixation Configurations. Master's Thesis, I-Shou University, Kaohsiung, Taiwan, 2013.

30. Rudderman, R.H.; Mullen, R.L. Biomechanics Of The Facial Skeleton. Clin. Plast. Surg. 1992, 19, 11-29. [CrossRef]

31. Schilli, W.; Stoll, P.; Bähr, W.; Prein, J. Mandibular Fractures. In Manual of Internal Fixation in the Cranio-Facial Skeleton: Techniques Recommended by the AO/ASIF Maxillofacial Group; Prein, J., Ed.; Springer: Berlin/Heidelberg, Germany, 1998; pp. 57-93. 